\title{
High-resolution Anorectal Manometry in the Diagnosis of Functional Defecation Disorder in Patients With Functional Constipation: A Retrospective Cohort Study
}

\author{
Yan Zhao, ${ }^{1}$ Xiaoyang Ren, ${ }^{1}$ Wen Qiao, ${ }^{1}$ Lei Dong, ${ }^{2}$ Shuixiang He, ${ }^{1 *}$ and Yan Yin $^{1 *}$ \\ ${ }^{1}$ Department of Gastroenterology, First Affiliated Hospital of Xi'an Jiaotong University, Shaanxi, China; and ${ }^{2}$ Department of Gastroenterology, \\ Second Affiliated Hospital of Xi'an Jiaotong University, Shaanxi, China
}

\begin{abstract}
Background/Aims
High-resolution anorectal manometry (HRAM) has been considered a first-line diagnostic tool for functional defecation disorder. However, clinical studies on HRAM used in constipation patients are very limited and few studies have reported the characteristics of anorectal pressure in Chinese patients. The aim of this study is to investigate the characteristics of motility data in a cohort of Chinese patients with functional constipation.

\section{Methods}

A total of 82 consecutive patients with functional constipation who underwent a standardized HRAM were retrospectively enrolled in this study. The functional defecation disorder was classified into Rao's types.
\end{abstract}

\section{Results}

The mean age of 82 patients was 51 years (range, 16-83 years). Indications for anorectal manometry were functional constipation for all patients. The mean resting pressure was $69.2 \pm 21.2 \mathrm{mmHg}$ (range, $24.5-126.9 \mathrm{mmHg}$ ). The mean maximum squeezing pressure was $198.4 \pm 75.6 \mathrm{mmHg}$ (range, $54.2-476.9 \mathrm{mmHg}$ ). The mean length of the anal high pressure zone was $3.4 \pm 1.0 \mathrm{~cm}$ (range, 0.6$4.9 \mathrm{~cm})$. Sixty $(73.2 \%)$ patients were diagnosed as functional defecation disorder. In attempted defecation, type I was most common ( $n=24)$, followed by type II $(n=12)$, type III $(n=11)$, and type IV $(n=13)$ that were present on HRAM according to Rao's classification. In all 60 patients with functional defecation disorder, 37 were women and 23 were men. Men were significantly more likely than women to have functional defecation disorder $(92.0 \%$ vs $64.9 \%, P=0.014)$.

\section{Conclusion}

HRAM could be used as a test for the diagnosis of functional defecation disorder and functional defecation disorder is common in Chinese patients with functional constipation.

(J Neurogastroenterol Motil 2019;25:250-257)

Key Words

Defecation; Humans; Manometry; Pressure

Received: February 14, 2018 Revised: January 25, 2019 Accepted: February 26, 2019

(a) This is an Open Access article distributed under the terms of the Creative Commons Attribution Non-Commercial License (http://creativecommons. org/licenses/by-nc/4.0) which permits unrestricted non-commercial use, distribution, and reproduction in any medium, provided the original work is properly cited.

${ }^{*}$ Correspondence: Shuixiang He and Yan Yin are equally responsible for this study. Shuixiang $\mathrm{He}, \mathrm{MD}$ Department of Gastroenterology, First Affiliated Hospital of Xi'an Jiaotong University, 277 West Yanta Road, Xi'an, Shaanxi 710061, China Tel: +86-2985323112, Fax: +86-2985323112, E-mail: hesx123@126.com

Yan Yin, MD Department of Gastroenterology, First Affiliated Hospital of Xi'an Jiaotong University, 277 West Yanta Road, Xi'an, Shaanxi 710061, China Tel: +86-2985323112, Fax: +86-2985323112, E-mail: yy1100002763@xjtu.edu.cn 


\section{Introduction}

In developed countries, functional anorectal disorders currently affect $10-25 \%$ of the population. ${ }^{1}$ Anorectal disorders, such as chronic functional constipation (FC), are common problems in clinical practice with slow transit colon or obstructed defecation syndrome, particularly for older people. Constipation affects up to 14$29 \%$ of adults in the Western countries, and about $8 \%$ of patients in eastern developed areas from China and the incidence rate is increasing because of an aging population. ${ }^{2-4}$ This number may be underestimated because most patients may not ask for health care. ${ }^{5}$

Evaluation of anorectal function is important to obtain information on the pathophysiology of the functional disorder because it helps to establish a proper diagnosis and for the selection of an adequate treatment modality. Currently, high-resolution anorectal manometry (HRAM) is used to determine anorectal pressure and has been considered a first-line diagnostic method for patients with functional defecation disorder. ${ }^{6}$ HRAM has several advantages, like providing greater physiologic resolution, minimizing movement artifact, etc. Therefore, HRAM is expected to help increase the diagnostic accuracy and finally direct the optimal therapy for patients with functional defecation disorders. However, this procedure was only carried out in a few specialist institutions and is not available in primary healthcare centers and secondary medical institutions. Until now, HRAM has been used mostly in the field of esophageal motility disorders but the results about the anorectal disorders are very limited. In addition, the clinical studies on HRAM used in constipation patients have been carried out mainly in Western countries, and data from the Asian area are very limited. Particularly, few studies have reported the characteristics of manometric data in Chinese patients and most of them were published in non-English journals. ${ }^{7,8}$ Therefore, our study was conducted to investigate the characteristics of anorectal pressure in a cohort of Chinese patients with FC.

\section{Materials and Methods}

\section{Study Population}

We enrolled consecutive patients with $\mathrm{FC}$ who were referred from Jan 2016 to March 2017 to our motility clinic at the First Affiliated Hospital of Xi'an Jiaotong University in Xi'an, China. Patients with FC were diagnosed according to the Rome IV criteria. ${ }^{9}$ Patients were excluded if there was a history of prior anorectal surgery, inflammatory bowel disease or anorectal malignancy. The study was approved by the Institutional Review Board (IRB No. XJTUAF2017LAK-30) and the informed consent was waived.

All patients finished the questionnaires about living habits, selfrating anxiety scale (SAS), and self-rating depression scale (SDS). The living habit questionnaires included the variables about smoking, alcohol abuse, daily water consumption, activity intensity, work position, diet, and dietary habits. Alcohol abuse was defined as greater than 14 standard drinks per week or greater than 4 standard drinks at one time. Activity intensity was divided as strong and moderate degrees, and strong degree means the daily work was mainly composed of physical activity. Work position was divided into stance and seat positions, and stance means more than half the time of daily work was finished in the standing position.

All patients underwent a balloon expulsion test before the HRAM as a screening test. A $4 \mathrm{~cm}$ long balloon filled with 50 $\mathrm{mL}$ of warm water was placed in the rectum. Then the patients were asked to expel the balloon after placement. The time from the start of pushing to expulsion of the balloon was recorded. It was considered that normal individuals could expel a balloon within one minute in this test. ${ }^{10}$

\section{High-resolution Anorectal Manometry Procedure}

A solid-state manometric assembly with 12 circumferential sensors (Sierra Scientific Instruments, Los Angeles, CA, USA) spaced at $0.6 \mathrm{~cm}$ intervals ( $4.2 \mathrm{~mm}$ outer diameter) was used. This device used proprietary pressure transduction technology that allowed each of the 12 pressure-sensing elements to detect pressure in each dispersed sectors. The sector pressures are then averaged, making each of the 12 sensors a circumferential pressure detector with the extended frequency response characteristic of solid-state manometric systems. Manometric data were analyzed by ManoView analysis software (Sierra Scientific Instruments).

Patients were asked not to take any medicine that may affect intestinal motility at least 3 days before the test. The HRAM was finished in the out-patient center and was normally done during 9-11 AM and 3-5 PM. Patients fasted during the whole process of the test. Patients were studied in the left lateral decubitus position with hips and knees flexed to $90^{\circ}$. Before the test patients were asked to defecate and a Glycerine enema would be given 2 hours prior to the study. All procedures were performed by a single experienced physician. The following variables were studied: maximum and mean resting pressures, maximum squeeze pressure, length of the anal high pressure zone (HPZ), intrarectal pressure, duration of sustained squeeze, residual anal pressure, rectoanal pressure differential 
(intrarectal pressure minus residual anal pressure), rectoanal inhibitor reflex, rectal balloon volumes for rectal first sensation, desire to defecatory sensation, urgency to defecate, and maximum tolerable volume.

After over 5 minutes of making the patients comfortable and allowing the pressures to be stable, the resting pressure and squeeze sphincter pressures were measured. Patients were asked to squeeze the anus for more than 20 seconds for 3 times with a 1 minute interval before the next squeezing. ${ }^{11}$ The eSleeve identified the highest of all pressures recorded by anal sensors at every point in time. By this eSleeve the average and maximum value of the anal resting pressure, and the maximum squeeze pressure over 20 seconds were calculated. ${ }^{12}$ Then the patients were asked to defecate for more than $20 \mathrm{sec}$ for 3 times and the balloon was not inflated. The residual pressure was measured during this process and it meant the sphincter pressure over a specified duration (usually set to 3 seconds) for which the recto-anal pressure differential was a maximum (Fig. 1). Recto-anal pressure differential was the average difference between the rectal and anal pressures taken over a specified duration for which this average difference was a maximum. Presence or absence of recto-anal inhibitory reflex was according to whether percent anal relaxation was greater than a specified percentage (usually set to $25 \%$ ). The percent anal relaxation was taken at its maximum value in the frame after balloon inflation was detected. The rectal balloon was initially distended with $10 \mathrm{~mL}$ of air. After 20 seconds, the balloon would be inflated in $10 \mathrm{~mL}$ steps up to a maximum of 50
$\mathrm{mL}$. The recto-anal inhibitory reflex was considered present if anal relaxation was greater than $25 \%$ after any time of balloon inflation. The length of HPZ was the length of average pressure profile in the resting pressure frame that was more than $25 \%$ of peak HPZ pressure above intrarectal pressure.

The balloon distension was performed by distending an elastic balloon, secured to a catheter placed in the rectum as measures of rectal sensitivity. The rectal balloon was manually inflated generally at the speed of $2.5 \mathrm{~mL} / \mathrm{sec}$ with a hand-held syringe. During balloon inflation, patients were instructed to report orally the perceived sensations including the first sensation, desire to defecate, urgency and maximum toleration or pain. The operators would keep asking the subjects about the feeling during the test. The distension at each of these sensory thresholds was then recorded. The inflation would be paused and would be continuously inflated after recording. ${ }^{13,14}$

Functional defecation disorders were characterized by paradoxical contraction or inadequate relaxation of the pelvic floor muscles during attempted defecation (dyssynergic defecation) or inadequate propulsive forces during attempted defecation (inadequate defecatory propulsion).

The diagnostic criteria for functional defecation disorders. ${ }^{15,16}$

(1) The patient must satisfy diagnostic criteria for functional constipation.

(2) During repeated attempts to defecate must have at least 2 of the following: (a) evidence of impaired evacuation based on balloon expulsion test; (b) inappropriate contraction of the pelvic floor

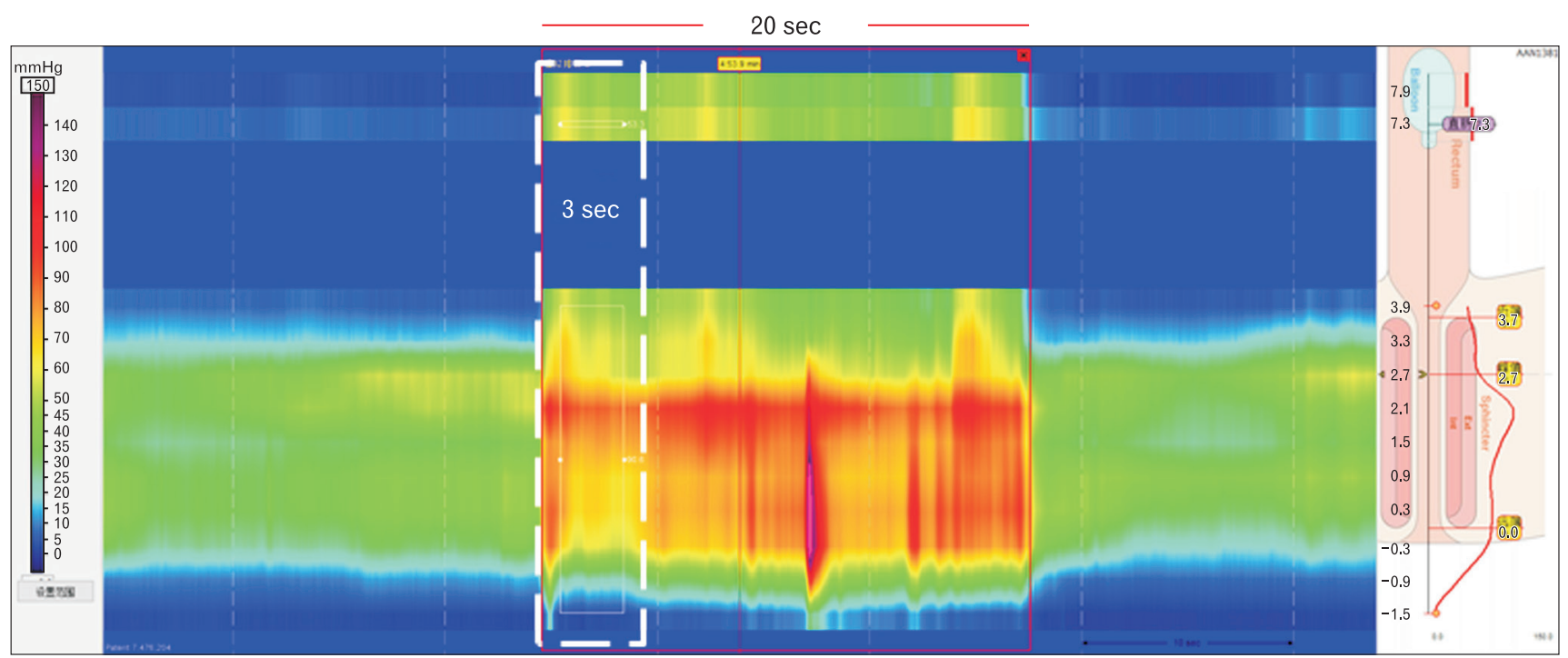

Figure 1. The measurement of residual pressure. The patients were asked to defecate for more than 20 seconds for 3 times and the balloon was not inflated. The residual pressure was measured during this process and it means the sphincter pressure over a specified duration (usually set to 3 seconds) for which recto-anal pressure differential is a maximum. 
muscles or inadequate propulsive forces by manometry or electromyography; and (c) impaired rectal evacuation by imaging.

The functional defection disorder was classified into Rao's types. ${ }^{17}$ During the defecation, normally the intrarectal pressure would increase and the intra-anal pressure would decrease. Type I was characterized by an increased intrarectal pressure $(\geq 45$ $\mathrm{mmHg}$ ) with a paradoxical increase in the intra-anal pressures. Type II, the subject could not generate an adequate propulsive force $(<45 \mathrm{mmHg})$ and had paradoxic anal contraction at the same time. In type III, the subjects were able to generate an adequate propulsive force ( $\geq 45 \mathrm{mmHg}$ ) but with incomplete or absent relaxation $(\leq 20 \%)$ of resting anal sphincter pressures. In type IV, the subjects could not generate an adequate propulsive force $(<45$ $\mathrm{mmHg}$ ) along with incomplete or absent relaxation of anal sphincter pressures. The types I and III were defined as dyssynergic defecation; while types I and IV were considered inadequate propulsion.

\section{Statistical Methods}

Continuous variables were summarized using means and standard deviations for normally distributed data. The medians and inter-quartile ranges were used to describe non-normal data. The categorical variables were expressed as proportions. Fisher's exact or chi-squared test was made for categorical variables and $t$ test or Wilcoxon's signed-rank test was made for normally or nonnormally distributed continuous data, respectively. A 2-tailed $P$ value less than 0.05 were considered to be of statistical significance. Statistical analyses were performed using SPSS version 17.0 (IBM Corp, Armonk, NY, USA).

\section{Results}

Of the 82 patients, the mean age was $51 \pm 1.7$ years (range, 16 83 years). The mean height and weight were $163.4 \pm 6.2 \mathrm{~cm}$ (range, $150.0-178.0 \mathrm{~cm}$ ) and $57.6 \pm 8.8 \mathrm{~kg}$ (range, 42.0-84.0 kg), respectively. The cohort included 25 men and 57 women. Indications for anorectal manometry were $\mathrm{FC}$ for all patients. Of the 82 patients, 60 (73.2\%) who expelled the balloon in more than 1 minute and had abnormal results for HRAM were diagnosed as functional defecation disorders. The median time interval between the last meal and the test was 2.6 hours (range, 2.0-4.0 hours).

For HRAM, the mean resting pressure was $69.2 \pm 21.2$ $\mathrm{mmHg}$ (range, 24.5-126.9 $\mathrm{mmHg}$ ). The mean maximum squeezing pressure was $198.4 \pm 75.6 \mathrm{mmHg}$ (range, 54.2-476.9 $\mathrm{mmHg}$ ). The mean length of $\mathrm{HPZ}$ was $3.4 \pm 1.0 \mathrm{~cm}$ (range, 0.6$4.9 \mathrm{~cm}$ ) (Table 1). The rectoanal pressure differential was nega- tive in 69 patients and the mean value was $-30.5 \pm 3.6 \mathrm{mmHg}$. Twenty-four patients had decreased relaxation of the anal sphincter with an absent relaxation or incomplete $(\leq 20 \%)$ relaxation of the resting anal sphincter pressure. Thirty-six patients had increased anal sphincter pressures. In addition, recto-anal inhibitor reflex was intact in 79 patients and was weakened in 3 cases. We compared the characteristics of anorectal pressure of patients with and without functional defecation disorders. The results showed that the patients without functional defecation disorders had less residual anal pressure (53.0 vs $91.7 \mathrm{mmHg}, P<0.001)$ (Table 2 ). In attempted defecation, type I was the most common $(\mathrm{n}=24)$ present on HRAM according to Rao's classification, followed by type II ( $\mathrm{n}=12)$, type III ( $\mathrm{n}=11)$, and type IV ( $\mathrm{n}=13)$ (Fig. 2). Thirty-five patients (type I and III) were diagnosed as dyssynergic defecation, and 25 patients (type II and IV) were diagnosed as inadequate defecatory propulsion.

In all 60 patients with functional defecation disorders, 37 were women and 23 were men. Men 23/25, 92\%) were significantly more likely than women $37 / 57,64.9 \%$ ) to have functional defecation disorders $(P=0.014)$. Duration of sustained squeeze was longer for women compared to men $(14.7 \pm 6.7$ vs $10.9 \pm 7.1 \mathrm{sec}-$ onds, $P=0.024)$. Residual anal pressure was higher for men than women $(106.6 \pm 35.7$ vs $70.2 \pm 27.3 \mathrm{mmHg}, P<0.001)$. There were no significant differences between men and women in mean volume of first sensation, desire to defecate, urgency, and maximum tolerable volume.

The potential related living habit variables including smoking, alcohol abuse, work position, etc. are listed in Table 3. However,

Table 1. Baseline Characteristics of Anorectal Pressure of Patients With Functional Constipation $(\mathrm{N}=82)$

\begin{tabular}{lc}
\hline \multicolumn{1}{c}{ Variables } & Values \\
\hline Maximum resting pressure $(\mathrm{mmHg})$ & $76.3 \pm 23.0$ \\
Mean resting pressure $(\mathrm{mmHg})$ & $69.2 \pm 21.2$ \\
Maximum squeeze pressure $(\mathrm{mmHg})$ & $198.4 \pm 75.6$ \\
HPZ length $(\mathrm{cm})$ & $3.4 \pm 1.0$ \\
Duration of sustained squeeze $(\mathrm{sec})$ & $13.6 \pm 7.0$ \\
Residual anal pressure $(\mathrm{mmHg})$ & $81.3 \pm 34.3$ \\
Intrarectal pressure $(\mathrm{mmHg})$ & $50.8 \pm 31.1$ \\
Rectoanal pressure differential $(\mathrm{mmHg})$ & $-30.5 \pm 3.6$ \\
Mean volume of first sensation $(\mathrm{mL})$ & $44.6 \pm 27.5$ \\
Mean volume for desire to defecate $(\mathrm{mL})$ & $77.6 \pm 35.0$ \\
Mean volume for urgency $(\mathrm{mL})$ & $109.0 \pm 35.6$ \\
Maximum tolerable volume $(\mathrm{mL})$ & $158.0 \pm 42.5$ \\
\hline
\end{tabular}

HPZ, high pressure zone.

Values were expressed as mean $\pm \mathrm{SD}$. 
Table 2. Characteristics of Anorectal Pressure Between Patients With and Without Functional Defecation Disorder

\begin{tabular}{|c|c|c|c|}
\hline Variables & $\begin{array}{l}\text { Functional defecation disorder } \\
\text { group }(n=60)\end{array}$ & $\begin{array}{l}\text { Non-functional defecation } \\
\text { disorder group }(\mathrm{n}=22)\end{array}$ & $P$-value \\
\hline Age (yr) & $51.9 \pm 18.8$ & $47.5 \pm 10.7$ & 0.177 \\
\hline Height (cm) & $163.0 \pm 6.6$ & $161.0 \pm 4.9$ & 0.095 \\
\hline Weight (kg) & $57.8 \pm 9.3$ & $57.6 \pm 7.4$ & 0.747 \\
\hline Maximum resting pressure ( $\mathrm{mmHg})$ & $76.8 \pm 25.0$ & $75.2 \pm 16.8$ & 0.740 \\
\hline Mean resting pressure $(\mathrm{mmHg})$ & $69.6 \pm 22.8$ & $68.3 \pm 16.4$ & 0.787 \\
\hline Maximum squeeze pressure (mmHg) & $197.6 \pm 79.0$ & $200.0 \pm 67.2$ & 0.872 \\
\hline HPZ length $(\mathrm{cm})$ & $3.5 \pm 1.0$ & $3.3 \pm 1.0$ & 0.389 \\
\hline Duration of sustained squeeze (sec) & $14.1 \pm 6.8$ & $12.1 \pm 7.4$ & 0.256 \\
\hline Rectoanal pressure differential ( $\mathrm{mmHg}$ ) & $-39.3 \pm 34.6$ & $-6.5 \pm 29.8$ & 0.508 \\
\hline Residual anal pressure (mmHg) & $91.7 \pm 33.3$ & $53.0 \pm 16.5$ & $<0.001$ \\
\hline Intrarectal pressure (mmHg) & $52.4 \pm 32.2$ & $46.4 \pm 28.0$ & 0.447 \\
\hline Mean volume of first sensation (mL) & $45.7 \pm 29.3$ & $41.8 \pm 22.4$ & 0.580 \\
\hline Mean volume for desire to defecate (mL) & $80.5 \pm 37.8$ & $69.5 \pm 24.6$ & 0.211 \\
\hline Mean volume for urgency (mL) & $112.0 \pm 37.2$ & $100.0 \pm 29.8$ & 0.172 \\
\hline Maximum tolerable volume (mL) & $162.0 \pm 41.9$ & $145.0 \pm 42.9$ & 0.129 \\
\hline
\end{tabular}

HPZ, high pressure zone.

Values were expressed as mean $\pm \mathrm{SD}$.
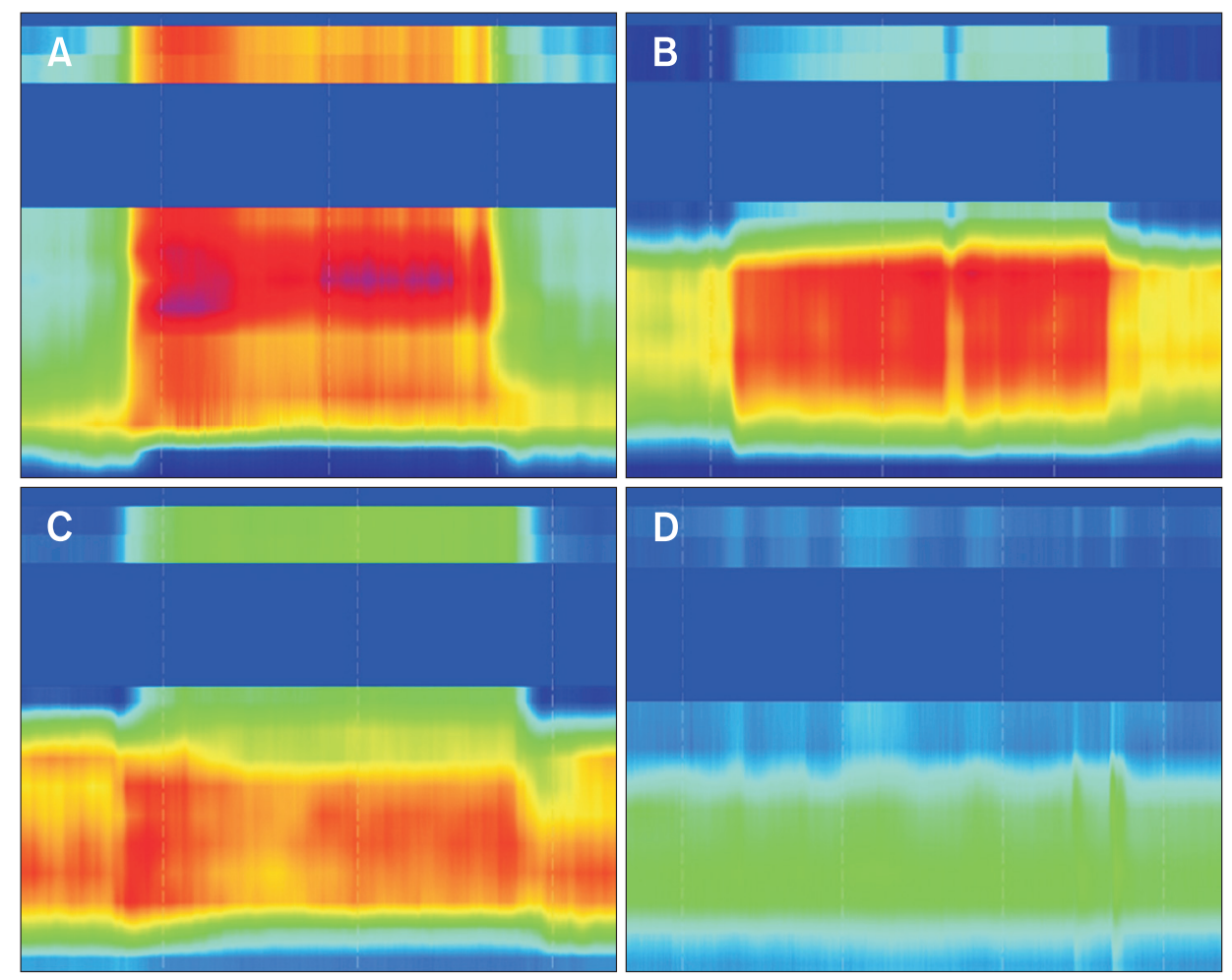

Figure 2. Representation of different types of functional defecation disorder during simulated defecation with highresolution anorectal manometry. (A) Type I, an increased intrarectal pressure with a paradoxical increase in the intra-anal pressure. (B) Type II, an inadequate intrarectal pressure with a paradoxical increase in the intra-anal pressure. (C) Type III, an adequate propulsive force along with an absent relaxation or incomplete $(\leq 20 \%)$ relaxation of resting anal sphincter pressure. (D) Type IV, an inadequate increase of intrarectal pressure with absent or incomplete relaxation of anal sphincter pressure. there was no difference between these 2 groups in terms of smoking, alcohol, water consumption, activity intensity, work position, diet, and dietary habit ( $P>0.05$ for all comparisons). In addition, we compared the SAS and SDS score for patients with and without functional defecation disorders. In total, 69 patients had complete data SAS and SDS reserve scores. For SAS scores, 22 patients in functional defecation disorder group had severe anxious symptoms with scores $>50$ compared with 8 patients in non-functional def- 
Table 3. Differences of Life Habits of Patients With Functional Constipation

\begin{tabular}{|c|c|c|c|}
\hline Variables & $\begin{array}{l}\text { Functional } \\
\text { defecation } \\
\text { disorder } \\
\text { group } \\
(\mathrm{n}=60)^{\mathrm{a}}\end{array}$ & $\begin{array}{l}\text { Non-func- } \\
\text { tional defeca- } \\
\text { tion disorder } \\
\text { group } \\
(\mathrm{n}=22)^{\mathrm{a}}\end{array}$ & $P$-value \\
\hline Smoking & & & 0.500 \\
\hline No & $47(73.4)$ & $17(84.6)$ & \\
\hline Yes & $11(26.6)$ & $2(15.4)$ & \\
\hline Alcohol abuse & & & $>0.99$ \\
\hline No & $54(93.1)$ & $18(94.7)$ & \\
\hline Yes & $4(6.9)$ & $1(5.3)$ & \\
\hline Daily water consumption & & & $>0.99$ \\
\hline$\geq 1 \mathrm{~L}$ & $35(60.3)$ & $12(63.2)$ & \\
\hline$<1 \mathrm{~L}$ & $23(39.7)$ & $7(36.9)$ & \\
\hline Activity intensity & & & 0.251 \\
\hline Strong & $19(39.6)$ & $4(22.2)$ & \\
\hline Moderate & $29(60.4)$ & $14(77.8)$ & \\
\hline Work position & & & 0.369 \\
\hline Stance & $16(28.1)$ & $3(15.8)$ & \\
\hline Seat & $41(71.9)$ & $16(84.2)$ & \\
\hline Diet & & & 0.133 \\
\hline Regular & $40(70.2)$ & $16(84.2)$ & \\
\hline Irregular & $17(29.8)$ & $3(15.8)$ & \\
\hline Dietary habit & & & 0.113 \\
\hline Vegetable based & $18(31.0)$ & $11(52.4)$ & \\
\hline Meat based & $40(69.0)$ & $10(47.6)$ & \\
\hline
\end{tabular}

${ }^{a}$ Some data about the life habit are missing and thus the total number in each group did not reach 60 and 22, respectively.

Values were expressed as n (\%).

ecation disorder group $(P=0.783)$. For SDS scores, 37 patients had severe depression symptoms in the functional defecation disorder group compared with 9 patients in the non-functional defecation disorder group $(P=0.246)$. Similarly, there was no significant difference of mean SAS score and SDS score between these 2 groups. The mean value of SAS scores of these 2 groups were 48.4 \pm 8.4 and $48.6 \pm 9.0$, respectively $(P=0.922)$. The mean value of the SDS score of the functional defecation disorder group and non-functional defecation disorder group was $54.2 \pm 11.6$ and 53.5 \pm 14.5 , respectively $(P=0.849)$. In addition, we compared the symptoms of patients with functional defecation disorders and those without functional defecation disorders in Table 4. For bowel habit, 52 patients in the functional defecation disorder group and 20 patients in the non-functional defecation disorder group had straining in at least $25 \%$ of defecations $(P=0.722)$. We failed to find the differences irrespective of hard or soft stools between these 2 groups.
Table 4. Comparison of Symptoms in Patients With and Without Functional Defecation Disorder

\begin{tabular}{|c|c|c|c|}
\hline Symptoms & $\begin{array}{c}\text { Functional } \\
\text { defecation } \\
\text { disorder } \\
\text { group } \\
(\mathrm{n}=60)\end{array}$ & $\begin{array}{c}\text { Non- } \\
\text { functional } \\
\text { defecation } \\
\text { disorder } \\
\text { group } \\
(\mathrm{n}=22)\end{array}$ & $P$-value \\
\hline Straining $^{\mathrm{a}}$ & $52(86.7)$ & $20(90.9)$ & 0.722 \\
\hline Lumpy or hard stools ${ }^{\mathrm{a}}$ & $17(28.3)$ & $6(27.3)$ & $>0.99$ \\
\hline $\begin{array}{l}\text { Sausage or snake, smooth and } \\
\text { soft stools }\end{array}$ & $12(20)$ & $7(31.8)$ & 0.375 \\
\hline $\begin{array}{l}\text { Sensation of incomplete } \\
\text { evacuation }^{\mathrm{a}}\end{array}$ & $41(68.3)$ & $14(63.6)$ & 0.792 \\
\hline $\begin{array}{l}\text { Sensation of anorectal } \\
\text { obstruction/blockage }^{\mathrm{a}}\end{array}$ & $18(30)$ & $2(9.1)$ & 0.080 \\
\hline Manual maneuvers to facilitate ${ }^{a}$ & $44(73.3)$ & $19(86.4)$ & 0.254 \\
\hline $\begin{array}{l}\text { Fewer than } 3 \text { spontaneous bowel } \\
\text { movements per week }\end{array}$ & $10(16.7)$ & $3(13.6)$ & $>0.99$ \\
\hline Mild abdominal pain & $28(46.7)$ & $11(50.0)$ & 0.808 \\
\hline $\begin{array}{l}\text { Minutes in lavatory per attempt } \\
(\geq 20 \mathrm{~min})\end{array}$ & $13(21.7)$ & $4(18.2)$ & $>0.99$ \\
\hline
\end{tabular}

${ }^{a}$ Symptoms present in at least $25 \%$ of defecations.

Values were expressed as n (\%).

Moreover, there was no statistical difference in terms of sensation of incomplete evacuation, sensation of anorectal obstruction/blockage, manual maneuvers to facilitate, fewer than 3 spontaneous bowel movements, mild abdominal pain and minutes in lavatory per attempt ( $\geq 20$ minutes) between the functional defecation disorder group and non-functional defecation disorder group.

\section{Discussion}

To date, most of the published studies on solid-state HRAM using ManoScan software have been limited to esophageal motility and the data about the characteristic of anorectal pressure are very rare. It was suggested that only 37 original articles have been published recently and most of them was been published in 20142015. ${ }^{18}$ However, the FC significantly impacts the quality of life and represents a serious medical problem. It could not differentiate the slow transit constipation from functional defecation disorders by symptoms alone. To date, functional defecation disorder is still an under-recognized cause for chronic constipation. It is particularly important to diagnose functional defecation disorder in patients with refractory chronic constipation as these patients respond better to anorectal biofeedback therapy than to laxatives. ${ }^{19,20}$ The assessment 
of the anorectum and pelvic floor by anorectal manometry provides crucial insights into the pathophysiologic processes underlying defecatory disorders and further help guide the optimal therapy.

The prevalence of functional defecation disorders in patients with chronic constipation ranges from $10 \%$ to $30 \%$ depending on the patient population and definition. ${ }^{21}$ According to a previous study, dyssynergic defecation was detected in $13-94 \%$ patients with $\mathrm{FC}^{22,23}$ Our study included a consecutive Chinese cohort of patients with $\mathrm{FC}$ and found that $73.2 \%$ patients were diagnosed as with functional defecation disorders by solid-state HRAM, and these patients may benefit from anorectal biofeedback therapy. Interestingly, we failed to find differences of living habits in terms of smoking, alcohol, water consumption, activity intensity, work position, diet, and dietary habits between patients in the functional defecation disorder group and without defecation disorder group.

In 2014, a multicenter study enrolled 166 Chinese healthy subjects and obtained the normative parameters with pneumohydraulic capillary perfusion system. ${ }^{7}$ The results showed that the mean value of normal length of the anal HPZ, resting pressures and maximum squeeze pressure were $3.6 \mathrm{~cm}$ (95\% confidence interval [CI], 2.4-4.6), $81.9 \mathrm{mmHg}$ (95\% CI, 47.7-132.1), and $155.6 \mathrm{mmHg}$ (95\% CI, 63.5-282.3), respectively. The rectal balloon volumes for rectal first sensation and maximum tolerable volume were $40 \mathrm{~mL}$ (95\% CI, 20-90) and $180 \mathrm{~mL}$ (95\% CI, 120-280), respectively. Compared to these results, the patients in our cohort showed shorter HPZ and, lower resting pressures, but higher maximum squeeze pressures. Interestingly, our data showed that patients with FC had higher volumes for rectal first sensation and lower maximum tolerable volume than healthy subjects. HRAM procedure was only carried out in very few specialist institutions and no available data reported the anorectal pressure under HRAM in Chinese patients, which makes it impossible for us to compare the data with other centers.

In addition, it was reported that higher resting and squeeze pressures are recorded in men compared with women, and age was associated with squeeze pressures. ${ }^{24,25}$ Zakari et al ${ }^{26}$ found that compared to women it seemed that men had higher median resting anal pressures and mean squeeze pressures. Different from this study, we did not find differences of resting anal pressure and squeeze pressure between women and men. We report sex based differences in the duration of sustained squeeze and residual anal pressures. Moreover, male patients with FC were significantly more likely than female patients to have functional defection disorders.

Our study has limitations. Firstly, we did not include healthy subjects for HRAM tests as a control group and thus we could not compare the anorectal pressure characteristics of functional defecation disorders patients with a healthy population. Secondly, we used HRAM in clinical practice rather than water-perfused anorectal manometry. Further studies are still required to confirm HRAM superiority over water-perfused anorectal manometry. Thirdly, although some of the patients with functional defecation disorders received biofeedback therapy, we failed to perform an overall follow up about their treatment efficacy, and therefore could not obtain the value of HRAM for functional defecation disorders. Fourthly, as we know, anorectal manometry parameters would have a rapid change after a meal according to previous reports. ${ }^{27-29}$ However, there is no consensus or standard about the fasting time before HRAM tests and the current studies rarely report the fasting conditions. In our study there was at least a 2 hour interval between the uptake and test. But there is no study to answer whether this interval is enough or not to avoid any effect of food. This issue brings about another interesting topic. That is to investigate the long-time change of anorectal manometry parameters after uptake under HRAM and finally help to decide the optimal time interval between test and meal.

In conclusion, our study provided comprehensive characteristics of motility patterns in Chinese patients with FC, which helped to enhance our understanding about the pathophysiology of functional defecation disorder in these areas. Further studies are urgently needed to compare the parameters under HRAM with the values of health population and follow up with the outcome of patients who received biofeedback therapy.

Financial support: This study was supported by Shaanxi Science Technology Co-ordination and Innovation Project (Grant No. 2016KTZDSF02-02).

\section{Conflicts of interest: None.}

Author contributions: Yan Zhao and Yan Yin: conception and design or analysis, and interpretation of data; Xiaoyang Ren, Wen Qiao, Lei Dong, and Shuixiang He: drafting the article or revising it critically for important intellectual content; and all authors final approved the version to be published.

\section{References}

1. Remes-Troche JM, Rao SS. Defecation disorders: neuromuscular aspects and treatment. Curr Gastroenterol Rep 2006;8:291-299.

2. Zhao YF, Ma XQ, Wang R, et al. Epidemiology of functional constipa- 
tion and comparison with constipation-predominant irritable bowel syndrome: the systematic investigation of gastrointestinal diseases in China (SILC). Aliment Pharmacol Ther 2011;34:1020-1029.

3. Pare P, Ferrazzi S, Thompson WG, Irvine EJ, Rance L. An epidemiological survey of constipation in canada: definitions, rates, demographics, and predictors of health care seeking. Am J Gastroenterol 2001;96:31303137.

4. Peppas G, Alexiou VG, Mourtzoukou E, Falagas ME. Epidemiology of constipation in Europe and Oceania: a systematic review. BMC Gastroenterol 2008;8:5.

5. Sonnenberg A, Koch TR. Physician visits in the United States for constipation: 1958 to 1986. Dig Dis Sci 1989;34:606-611.

6. Noelting J, Ratuapli SK, Bharucha AE, Harvey DM, Ravi K, Zinsmeister AR. Normal values for high-resolution anorectal manometry in healthy women: effects of age and significance of rectoanal gradient. Am J Gastroenterol 2012;107:1530-1536.

7. Sun $\mathrm{X}$, Wang Z, Xin H, et al. Normative values and its clinical significance of the anorectal manometry in Chinese from multi-center study. Chin J Dig 2014:597-602.

8. Wang AJ, Shi YQ, Zheng XL, et al. Normal values for solid state high resolution anorectal manometry in healthy adult volunteers. Chin J Intern Med 2017;56:572-576.

9. Mearin F, Lacy BE, Chang L, et al. Bowel disorders. Gastroenterology 2016;150:1393-1407, e5.

10. Minguez M, Herreros B, Sanchiz V, et al. Predictive value of the balloon expulsion test for excluding the diagnosis of pelvic floor dyssynergia in constipation. Gastroenterology 2004;126:57-62.

11. Kang HR, Lee JE, Lee JS, et al. Comparison of high-resolution anorectal manometry with water-perfused anorectal manometry. J Neurogastroenterol Motil 2015;21:126-132.

12. Lee TH, Bharucha AE. How to perform and interpret a high-resolution anorectal manometry test. J Neurogastroenterol Motil 2016;22:46-59.

13. Scott SM, Gladman MA. Manometric, sensorimotor, and neurophysiologic evaluation of anorectal function. Gastroenterol Clin North Am 2008;37:511-538.

14. Carrington EV, Scott SM, Bharucha A, et al. Expert consensus document: advances in the evaluation of anorectal function. Nat Rev Gastroenterol Hepatol 2018;15:309-323.

15. Bharucha AE, Wald A, Enck P, Rao S. Functional anorectal disorders. Gastroenterology 2006;130:1510-1518.

16. Drossman DA. Functional gastrointestinal disorders: history, pathophysiology, clinical features and rome IV. Gastroenterology 2016;150:1262-
1279, e2.

17. Lee YY, Erdogan A, Rao SS. High resolution and high definition anorectal manometry and pressure topography: diagnostic advance or a new kid on the block? Curr Gastroenterol Rep 2013;15:360.

18. Dinning PG, Carrington EV, Scott SM. Colonic and anorectal motility testing in the high-resolution era. Curr Opin Gastroenterol 2016;32:4448.

19. Chiarioni G, Whitehead WE, Pezza V, Morelli A, Bassotti G. Biofeedback is superior to laxatives for normal transit constipation due to pelvic floor dyssynergia. Gastroenterology 2006;130:657-664.

20. Jones MP, Post J, Crowell MD. High-resolution manometry in the evaluation of anorectal disorders: a simultaneous comparison with waterperfused manometry. Am J Gastroenterol 2007;102:850-855.

21. Skardoon GR, Khera AJ, Emmanuel AV, Burgell RE. Review article: dyssynergic defaecation and biofeedback therapy in the pathophysiology and management of functional constipation. Aliment Pharmacol Ther 2017;46:410-423.

22. Rao SS, Patcharatrakul T. Diagnosis and treatment of dyssynergic defecation. J Neurogastroenterol Motil 2016;22:423-435.

23. Grossi U, Carrington EV, Bharucha AE, Horrocks EJ, Scott SM, Knowles CH. Diagnostic accuracy study of anorectal manometry for diagnosis of dyssynergic defecation. Gut 2016;65:447-455.

24. Carrington EV, Brokjaer A, Craven H, et al. Traditional measures of normal anal sphincter function using high-resolution anorectal manometry (HRAM) in 115 healthy volunteers. Neurogastroenterol Motil 2014;26:625-635.

25. Lee HJ, Jung KW, Han S, et al. Normal values for high-resolution anorectal manometry/topography in a healthy Korean population and the effects of gender and body mass index. Neurogastroenterol Motil 2014;26:529-537.

26. Zakari M, Nee J, Hirsch W, Kuo B, Lembo A, Staller K. Gender differences in chronic constipation on anorectal motility. Neurogastroenterol Motil 2017;29:e12980.

27. Walter SA, Morren GL, Ryn AK, Hallböök O. Rectal pressure response to a meal in patients with high spinal cord injury. Arch Phys Med Rehabil 2003;84:108-111.

28. Leroi AM, Saiter C, Roussignol C, Weber J, Denis P. Increased tone of the rectal wall in response to feeding persists in patients with cauda equina syndrome. Neurogastroenterol Motil 1999;11:243-245.

29. Bell AM, Pemberton JH, Hanson RB, Zinsmeister AR. Variations in muscle tone of the human rectum: recordings with an electromechanical barostat. Am J Physiol 1991;260(1 Pt 1):G17-G25. 